\title{
Prenatal care utilization in rural areas and urban areas of Haiti
}

\author{
Pierre Kébreau Alexandre, ${ }^{1}$ Gilbert Saint-Jean, ${ }^{2}$ Lee Crandall, ${ }^{2}$ \\ and Etzer Fevrin ${ }^{3}$
}

Suggested citiation

Alexandre PK, Saint-Jean G, Crandall L, Fevrin E. Prenatal care utilization in rural areas and urban areas of Haiti. Rev Panam Salud Publica. 2005;18(2):84-92.

ABSTRACT Objectives. This study is based on the 2000 Demographic and Health Survey (DHS) conducted in Haiti. Using the DHS information on women aged 15 to 49 who had given birth during the three years preceding the survey interview, this study was intended to: (1) examine the determinants of the likelihood of the women using prenatal care in the rural areas and in the urban areas of the country and (2) for the women who made at least one prenatal care visit, examine the determinants of the number of prenatal visits in the rural areas and the urban areas. Methods. The multivariate analysis used logistic models to identify which factors explained the decision to seek prenatal care, and negative binomial models were used to determine how many prenatal visits were conducted by the subgroup of women who did make prenatal care visits.

Results. Estimated at the mean values of the control variables, the expected probability of using prenatal care services in rural Haiti was $77.16 \%$, compared to $85.83 \%$ in urban Haiti. Among users of prenatal care services, mothers in rural areas made an expected number of 3.78 prenatal care visits, compared to 5.06 visits for the women in urban areas.

Conclusions. A substantial percentage of pregnant women have access to prenatal care services in Haiti, but mothers in rural areas who decided to seek care still fell slightly below the four visits recommended by the World Health Organization. The education levels of both mothers and their partners is a dominant predictor of prenatal care use. Longer travel times and greater distances to health centers in rural areas constituted barriers to repeated visits. Policymakers and health care providers need to take these findings into consideration as they decide on the delivery and management of health care services in Haiti.

Key words Prenatal care, rural health services, urban health services, Haiti.

1 The Johns Hopkins University, Bloomberg School of Public Health, Department of Mental Health, Baltimore, Maryland, United States of America. Send correspondence to: Pierre K. Alexandre, Department of Mental Health, Room 833, Bloomberg School of Public Health, The Johns Hopkins University, Baltimore, Maryland 21205, United States of America; telephone: 410-502-2588; fax: 410-9559088; e-mail: pialexan@jhsph.edu

2 University of Miami, School of Medicine, Department of Epidemiology and Public Health and Health Services Research Center, Miami, Florida, United States of America.

3 HaitiData, Delmas, Haiti, and Faculté d'Agronomie et de Médecine Vétérinaire, Damien, Haiti.
During the past several decades, improvements in health care have led to decreased mortality throughout the developing world. However, health conditions in Haiti have generally remained poor. For example, the infant mortality rate in the year 2000 was estimated at 74 per 1000 live births, the incidence of low birthweight at $15 \%$, and the maternal death ratio at 456 per 100000 live births (1). While prenatal care interventions alone do not address all the causes of health care complications and mortalities associated with pregnancy, major efforts have been made in the developing world to assure that pregnant women have access to adequate prenatal care. The use of prenatal care services in Latin America and the Caribbean increased by approximately $14 \%$ between 1990 and 2000. However, urban and rural 
differentials in prenatal care use within countries are striking (1).

In Haiti there are wide disparities between the rural and urban areas, with the rural areas being worse off in terms of both economic and health conditions. Over decades, population pressure, poor land use, and public policies forced cultivation of increasingly marginal lands, which has caused accelerated deforestation, soil erosion, and depletion of water sources and other natural resources. This has had a direct and devastating impact on agricultural production, the main source of income for the rural residents, who make up $63 \%$ of the country's population (1). Approximately $80 \%$ of the rural population lives below the poverty line (2).

An unequal distribution of government resources and other resources between rural and urban Haiti has also contributed to these inequalities. Rural areas receive only $20 \%$ of public investment (2). While $47 \%$ of the urban population can reach a health care facility in less than 30 minutes, $34 \%$ of the rural population needs two hours or more (3). In rural areas, nurse auxiliaries in health centers (dispensaries), along with traditional birth attendants or midwives, provide the bulk of health care to pregnant women. The objectives of this study were twofold: (1) to examine the determinants of the likelihood of using prenatal care in rural and urban Haiti and (2) to examine the determinants of the number of prenatal visits in rural and urban areas for the women who had a least one prenatal care visit.

\section{MODEL AND ESTIMATION ISSUES}

A commonly applied model to study access to or use of health services is the Andersen/Aday social behavioral model. That model organizes factors related to health care service utilization into three categories: (1) predisposing factors, which shape attitudes toward service use; (2) enabling factors, that is, resources that promote or inhibit use; and (3) need factors, which encompass the individual's illness or impairment that necessitates health care use $(4,5)$. Mostly used by economists, another set of theoretical approaches has been developed to focus on how individuals make decisions on consuming health care to produce health (6-9). These approaches follow the health production aspects of human capital theory and describe the demand for health care through a household production process for good health. Based on these models, pregnant women would consume health care not for its direct pleasure but for the effect that health care has on health status, and, consequently, on overall utility or wellbeing of both mothers and expected newborns. Individuals are utility maximizers, who face a budget constraint that limits the amount of health care (and other goods) that they can consume. Solving this constrained maximization problem provides the demand relationship for each good and service in the person's overall utility function, including health care (10). Several factors enter this consumer behavior model, including income available to the individual, behavioral and personal characteristics that influence preferences and tastes, and environmental factors such as availability of services and other resources.

Researchers have generally estimated one-step econometric models based on the traditional consumer theory approach $(11,12)$. However, in many recent empirical studies of health care utilization the two-part model (TPM) has served as a cornerstone of analysis (13-20). The TPM is often interpreted as a principal-agent type of model, in which the physician (agent) determines utilization on behalf of the patient (principal) once initial contact has been made (21). TPMs represent the utilization decision with two equations. The first stage, or "hurdle component," identifies which factors determine the decision to seek any care. The second equation, or "levels component," determines how much care is demanded by the persons who pass the first hurdle and do receive some care (22). TPMs thus recognize that women who used prenatal care services may behave differently from those who did not. For this reason, TPMs are potentially superior to singleequation models in predicting use of care and responses to various demand stimuli $(17,20,23)$.

TPMs estimate the first part as a simple binary outcome process, but the choice of the econometric technique in the second part must consider the long tails of the distributions of health care services. The values for health services measures (such as medical doctor visits and emergency room episodes) are typically clustered around zero and small integer numbers for the vast majority of the observations $(11,24,25)$. The second part of TPMs thus has been adapted to accommodate count measures or episodes of care using the flexible family of negative binomial distributions (13, $15,16,26)$. This study used a logistic model to examine the probability of using any prenatal care (the "hurdle component"), and a truncated negative binomial model to estimate the number of prenatal care visits among women who had at least one visit.

The choice of a theoretical framework depends on the unit of analysis chosen, but any utilization model must explore the determinants of need, supply, and the health care system (5). We incorporated sociodemographic variables that various studies in developing countries have found to be important correlates of health care utilization (27-33). The control variables in our empirical analysis thus include sociodemographic variables coded in the following manner: respondent's age (15 to 24,25 to 34 , and 35 to 49 years), marital status (married or cohabiting vs. others), education (no education, primary, and at least a secondary education level), religion (Protestant, Catholic, and atheist (Vodou or no religion)), age at first birth, the number of children under five living in the household, employment any time within the past 12 months (employed vs. unemployed), ever used contraceptive methods (yes vs. no), and whether the 
woman wanted to have a child at the time of the pregnancy. Similar to the maternal education indictor, a variable was included to represent the education level of the man living with the woman at the time of the survey. The international public health literature has often ignored the supportive role of relatives in family health, but that role has been documented in many developing countries (34-38). We thus incorporated a composite variable representing family support, which indicated whether there was a family member living with the respondent or within walking distance of her, or whether the respondent received economic support from family members. Finally, needs variables that could be a cause of prenatal care use included smoking status, whether the mother had previously had an abortion, and her body mass index. Enabling factors referred to community resources that influenced prenatal care access. They included whether mothers were aware of where to go in case of pregnancy complications, distance to the nearest hospital, distance to the nearest dispensary, and whether roads to the nearest hospital or dispensary represented major difficulties $(1,28)$.

\section{SAMPLE AND DATA}

The study used the 2000 EMMUS-III (Enquête Mortalité, Morbidité et Utilisation des Services (Survey on Mortality, Morbidity, and Services Use)) dataset of the Haiti-Demographics and Health Survey (Haiti-DHS) series, which is an ongoing project implemented by the Institut Haitien de l'Enfance (Haitian Children's Institute), a research institution that is based in the country's capital, Port-au-Prince, and that focuses on children's issues. Conducted by the Haitian Children's Institute, the 2000 EMMUS-III survey is the third in a series that has been implemented since 1987. The second survey was implemented in 1994-1995. ORC Macro International Inc., a firm located in the state of Maryland, United States, provided technical assistance for the survey through the MEASURE
DHS+ program. Funded by the United States Agency for International Development, the MEASURE DHS+ program assists developing countries in collecting data on fertility, family planning, and maternal and child health. The survey methods for the 2000 EMMUS-III dataset as well as univariate tabulations have been described in an overview report (3). In 2000 the EMMUS-III surveyed a total of 9595 households in Haiti's nine departments. These departments were divided into 9 urban and 9 rural strata plus the metropolitan area of Port-auPrince, for a total of 19 strata.

A two-stage sampling procedure was used to select a representative sample of the target population. In the first stage, systematic sampling with probability proportional to the size of the strata was used to select 317 primary sampling units (PSUs) -142 in urban areas and 175 in rural areasfrom the frame of census enumeration areas established by the Institut Haitien de Statistique et d'Informatique (Haitian Institute for Statistics and Informatics) from the 1982 population census. The frame was updated using the 1996 population census. In the second stage of sampling, households in each of the PSUs were systematically sampled so as to provide statistically reliable estimates of key demographic and health variables for the urban and rural areas of the country as a whole (3).

Information in the 2000 EMMUS-III survey was collected by trained Haitian nationals, who conducted face-toface interviews in Creole. The survey incorporated a household questionnaire, a men's questionnaire, a women's questionnaire, and a community questionnaire. Two of the questionnaires were of primary interest for this study: the women's questionnaire and the community questionnaire. We merged these two questionnaires, using the PSUs. All women aged 15 to 49 years old who were present in the households were interviewed, giving a total of 10399 eligible women for the 9595 households. Of the 10399 eligible women, 10159 of them $(97.7 \%)$ answered the women's questionnaire. The individual questionnaire for women obtained information about the following subjects: female respondent's background characteristics, including age, marital status, education, employment, and place of residence; reproductive history; knowledge and use of family planning methods; antenatal, delivery, and postpartum care; breast-feeding and infant feeding practices; vaccinations and childhood illnesses; partner's background, including age, education, and occupation; and other topics, including the woman's awareness and behavior regarding AIDS and other sexually transmitted infections. We used the information on the women who selfreported having given birth during the three years preceding the interview date, covering a total of 3436 observations, of which $69.6 \%$ of them were collected in rural areas and $30.4 \%$ in urban areas. Women who reported more than one pregnancy during the three-year period (18\%) were asked to focus on the most recent pregnancy. To obtain information on the availability of and accessibility to health care institutions, we merged the women's sample with the community questionnaire. Each community questionnaire applied to a specific PSU. Information for the community questionnaire was obtained by interviewing a group of well-informed individuals from local governments, schools, churches, and health institutions in each of the respective PSUs.

The following section presents the summary statistics for the prenatal care measures and the control variables used in the multivariate analyses. Nonparametric Kruskal-Wallis rank sum tests were used to test for significant differences in these variables between urban and rural respondents. We also present the results from the multivariate logistic regressions, which estimated the likelihood of seeking prenatal care for all the respondents. The section ends with the results from the negative binomial models, which calculated prenatal care visits for women who had at least one visit. The multivariate models were separately estimated for women in urban and rural areas. 


\section{RESULTS}

\section{Summary statistics}

Table 1 presents summary statistics of the measures used in the study. In addition to overall sample means, values are reported by residency, that is, rural and urban. Residency was determined by the current place of living, that is, in 2000. Eight percent of the women surveyed who were living in rural areas had relocated from urban areas during the preceding three years, whereas $12 \%$ of the urban women had moved from rural areas during the preceding three years. We used Kruskal-Wallis rank sum tests to determine statistical differences between the rural and urban samples for the prenatal care measures as well as for the control variables used in the multivariate analyses.
Of the women surveyed, $87 \%$ of the ones residing in cities used prenatal services, compared to $74 \%$ for the rural sample $(P \leq 0.01)$. Among mothers who used prenatal care services, those living in urban areas reported a mean of 5.14 visits, compared to 3.84 visits for mothers living in rural areas. Urban mothers tended to be younger on average, waited longer before they had their first babies, and had significantly fewer children under five in their households. These findings indicate that mothers in rural Haiti not only had their first babies earlier than did the mothers in cities but also continued to have more children as they moved into the upper childbearing age brackets. We also found that both the urban women and their partners had more formal education than did their rural counterparts. A higher percentage of urban mothers reported having ever used contraceptive methods, wanted to have a baby at the time of the most recent pregnancy, and knew where to go to seek help in case of pregnancy complications. In comparison to the mothers in urban areas, the mothers in the rural areas had a lower body mass index, were more likely to be married/cohabiting, and were more likely to have held a job sometime during the preceding 12 months. Finally, as expected, the mothers in rural areas had significantly greater difficulties gaining access to health care facilities, both in terms of distance and road conditions.

The following subsection describes the results of the multivariate analysis, which estimated both the decision for pregnant women to seek prenatal care services and the levels of utilization among the mothers who did seek prenatal care services. As noted earlier, to

TABLE 1. Prenatal care use and other characteristics for women in rural and urban Haiti, 2000

\begin{tabular}{|c|c|c|c|c|c|c|}
\hline \multirow[b]{2}{*}{ Variable } & \multicolumn{2}{|c|}{$\begin{array}{c}\text { Rural } \\
(n=2392)\end{array}$} & \multicolumn{2}{|c|}{$\begin{array}{c}\text { Urban } \\
(n=1044)\end{array}$} & \multicolumn{2}{|c|}{$\begin{array}{l}\text { Full sample } \\
(n=3436)\end{array}$} \\
\hline & Mean & SE ${ }^{a}$ & Mean & SE & Mean & SE \\
\hline Prenatal care use $(\%)^{\mathrm{b}}$ & 73.58 & $N A^{c}$ & 87.07 & NA & 77.68 & NA \\
\hline Conditional prenatal visits ${ }^{b, d}$ & 3.84 & 2.15 & 5.14 & 2.66 & 4.28 & 2.42 \\
\hline Age $15-24(\%)^{b}$ & 29.10 & NA & 33.72 & NA & 30.50 & NA \\
\hline Age 25-34 (\%) & 43.02 & NA & 46.17 & NA & 43.98 & NA \\
\hline Age $35-49(\%)^{b}$ & 27.88 & NA & 20.11 & NA & 25.52 & NA \\
\hline Woman has no education (\%) ${ }^{\mathrm{b}}$ & 46.95 & NA & 20.88 & NA & 39.03 & NA \\
\hline Woman has primary education (\%) & 45.90 & NA & 44.54 & NA & 45.49 & NA \\
\hline Woman has at least secondary education (\%) & 7.15 & NA & 34.58 & NA & 15.48 & NA \\
\hline Protestant $(\%)$ & 39.13 & NA & 37.74 & NA & 38.71 & NA \\
\hline Catholic (\%) & 51.96 & $\mathrm{NA}$ & 53.07 & NA & 52.30 & NA \\
\hline Atheist $(\%)$ & 8.90 & NA & 9.20 & NA & 91.01 & NA \\
\hline Married or cohabiting (\%) ${ }^{\mathrm{b}}$ & 90.01 & NA & 82.95 & NA & 87.86 & NA \\
\hline Number of children under five in household ${ }^{b}$ & 2.00 & 1.00 & 1.64 & 0.95 & 1.89 & 0.99 \\
\hline Mother's age at first birth (years) ${ }^{b}$ & 20.39 & NA & 21.09 & NA & 20.60 & NA \\
\hline Ever had an abortion (\%) & 13.71 & NA & 12.16 & NA & 13.24 & NA \\
\hline Ever used contraception (\%) ${ }^{\mathrm{b}}$ & 48.41 & NA & 63.51 & NA & 53.00 & NA \\
\hline Wanted most recent pregnancy $(\%)^{\mathrm{b}}$ & 37.88 & NA & 43.77 & NA & 39.67 & NA \\
\hline Employed sometime in the past 12 months $(\%)^{\mathrm{b}}$ & 56.40 & NA & 48.75 & NA & 54.07 & NA \\
\hline Body mass index ${ }^{b}$ & 21.93 & 3.40 & 23.61 & 4.19 & 22.44 & 3.74 \\
\hline Smoker (\%) & 4.98 & NA & 4.02 & NA & 4.69 & NA \\
\hline Aware of where to go for pregnancy complications (\%) & 90.68 & NA & 94.64 & NA & 91.88 & NA \\
\hline Partner has no education $(\%)^{\mathrm{b}}$ & 42.73 & NA & 18.35 & NA & 35.42 & NA \\
\hline Partner has primary education (\%) ${ }^{b}$ & 42.39 & NA & 33.03 & NA & 39.58 & NA \\
\hline Partner has at least secondary education (\%) ${ }^{b}$ & 14.88 & NA & 48.61 & NA & 25.00 & NA \\
\hline Received support from relatives and family members (\%) & 46.36 & NA & 46.93 & NA & 46.54 & NA \\
\hline Distance to nearest hospital $(\mathrm{km})^{\mathrm{b}}$ & 28.05 & 25.18 & 9.31 & 17.90 & 22.36 & 24.76 \\
\hline Distance to nearest health center $(\mathrm{km})^{\mathrm{b}}$ & 22.20 & 24.73 & 5.90 & 9.28 & 17.24 & 22.54 \\
\hline Roads represented major difficulties (\%) & 48.66 & NA & 20.11 & NA & 39.99 & NA \\
\hline
\end{tabular}


fulfill the objectives of the study and bring further insights into the analysis, we estimated separate models for urban areas and rural areas in Haiti.

\section{Seeking prenatal care}

Mothers in rural areas. The second column in Table 2 presents the odds ratios (ORs) from the multivariate logistic analysis of the probability of seeking prenatal care for women, ages 15 to 49 , who were living in rural Haiti and who reported having given birth during the three years preceding the interview date. The estimated standard errors are presented in the third column of Table 2. The chi-square Pearson goodness of fit $(P=0.57)$ indicates that our model for the rural areas fits the data reasonably well.

Many variables were important predictors of the probability of using prenatal care in rural Haiti. First, educa- tion of either the pregnant woman or her partner was positively related to the likelihood of prenatal care use. More specifically, compared to women who had no education, women in rural Haiti who had completed primary school were more than twice as likely to use prenatal care services, and those who had at least a secondary education level were more than three times as likely to use these services. Compared to rural women whose partner had no education, rural women whose partner had a primary education were $30 \%$ more likely to use prenatal care, and the rural women whose partner had at least a secondary education level were almost three times as likely to do so. Being Catholic or Protestant was positively and significantly related to the propensity for utilizing prenatal care, relative to being an atheist. Compared to single women, women who were married or cohabiting were more likely to use prenatal services. The older the rural mothers were when they had their first baby, the higher was their likelihood of using prenatal care. Other factors that significantly increased the likelihood of using prenatal care in rural Haiti included that the woman had used a contraceptive method at some point, that she had wanted the most recent pregnancy, that the woman had a higher body mass index, and that the woman knew where to go in case of pregnancy complications.

Mothers in urban areas. The odds ratios from the multivariate logistic model of prenatal care use in urban Haiti are presented in the fourth column in Table 2, and the estimated standard errors are given in the last column. The chi-squared Pearson goodness of fit $(P=0.15)$ indicates that the model for urban Haiti fits reasonably well. The results indicate that mothers in urban Haiti who had at least a secondary education were more

TABLE 2. Odds ratio for prenatal care use estimated from multivariate logistic regressions for mothers in urban and rural Haiti, 2000

\begin{tabular}{|c|c|c|c|c|}
\hline \multirow[b]{2}{*}{ Variable } & \multicolumn{2}{|c|}{$\begin{array}{c}\text { Rural } \\
(n=2392)\end{array}$} & \multicolumn{2}{|c|}{$\begin{array}{c}\text { Urban } \\
(n=1044)\end{array}$} \\
\hline & Odds ratio & Standard error & Odds ratio & Standard error \\
\hline Age 15-24 & 1.00 & - & 1.00 & - \\
\hline Age 25-34 & 0.9998 & 0.1369 & 1.0572 & 0.2671 \\
\hline Age $35-49$ & 0.8818 & 0.1423 & 1.0077 & 0.3320 \\
\hline Woman has no education & 1.00 & - & 1.00 & - \\
\hline Woman has primary education & $2.1343^{a}$ & 0.2461 & 1.3294 & 0.3186 \\
\hline Woman has at least secondary education & $3.4604^{\mathrm{a}}$ & 1.1921 & $2.0645^{\mathrm{b}}$ & 0.7171 \\
\hline Atheist & 1.00 & - & 1.00 & - \\
\hline Protestant & $1.6289^{a}$ & 0.2872 & $2.9749^{a}$ & 1.0015 \\
\hline Catholic & $1.3937^{\mathrm{b}}$ & 0.2351 & 1.4639 & 0.4231 \\
\hline Single & 1.00 & - & 1.00 & - \\
\hline Married or cohabiting & $1.5424^{b}$ & 0.2704 & 1.2530 & 0.3368 \\
\hline Number of children under five in household & 0.9049 & 0.0466 & 1.2065 & 0.1323 \\
\hline Mother's age at first birth & $1.0380^{b}$ & 0.0152 & 1.0299 & 0.294 \\
\hline Ever had an abortion & 1.0237 & 0.1480 & 0.9463 & 0.2993 \\
\hline Ever used contraception & $1.5933^{\mathrm{a}}$ & 0.1666 & 1.2416 & 0.2631 \\
\hline Most recent pregnancy was wanted & $1.3367^{a}$ & 0.1481 & $2.1364^{\mathrm{a}}$ & 0.4793 \\
\hline Employed sometime in the past 12 months & 1.1562 & 0.1179 & 1.0213 & 0.2079 \\
\hline Body mass index & $1.0005^{\mathrm{a}}$ & 0.0002 & 1.0001 & 0.0003 \\
\hline Smoker & 0.7046 & 0.1483 & 1.0533 & 0.4735 \\
\hline Aware of where to go for pregnancy complications & $1.5259^{\mathrm{a}}$ & 0.2467 & 0.9857 & 0.4017 \\
\hline Partner has no education & 1.00 & - & 1.00 & - \\
\hline Partner has primary education & $1.2983^{b}$ & 0.1413 & 0.8911 & 0.2244 \\
\hline Partner has at least secondary education & $2.6175^{a}$ & 0.5749 & $1.9005^{b}$ & 0.5849 \\
\hline Received support from relatives and family members & 1.0883 & 0.1097 & 0.9924 & 0.1974 \\
\hline Distance to nearest hospital & 0.9999 & 0.0022 & 1.0060 & 0.0065 \\
\hline Distance to nearest health center & 0.9991 & 0.0022 & 1.0065 & 0.0118 \\
\hline Roads represented major difficulties & 0.8542 & 0.0889 & 0.8666 & 0.2061 \\
\hline
\end{tabular}

\footnotetext{
a Statistically significant, $P \leq 0.01$.
}

b Statistically significant, $P \leq 0.05$. 
than twice as likely to use prenatal care services, compared to urban women who had no education. But, unlike in rural Haiti, there were no significant differences between urban mothers with no education and those with a primary education in seeking prenatal care. Compared to urban mothers whose partners had no education, the mothers whose partners had at least a secondary level of education were almost twice as likely to use prenatal care. We found that Protestantism was positively and significantly related to the likelihood of seeking prenatal care. However, contrary to rural Haiti, there was no significant difference between mothers who reported being Catholic and those who practiced Vodou or had no religion. Mothers in urban Haiti who reported that they wanted the most recent pregnancy were twice as likely to use prenatal care services.

\section{Levels of prenatal care among users}

Mothers in rural areas. As indicated earlier in this article, we used negative binomial models to estimate the levels of use of prenatal care services among women of childbearing age in rural Haiti who had both given birth and used prenatal care services during the three years preceding the interview. The estimation results for the rural women are presented in the second and third columns of Table 3. Rather than presenting the underlying coefficient estimates from the negative binomial models, we calculated relative incidence rate ratios (IRRs). The IRRs are calculated as $\mathrm{e}^{\beta}$, where e is the exponential and $\beta$ is the coefficient estimate The IRRs allow us to compare rates. For example, with the variable "secondary education" in Table 3, the interpretation is that, keeping every- thing else constant, rural women who had a secondary education were expected to receive 1.22 times the number of prenatal care visits as were the rural women with no education.

The main result was that, estimated at the mean values of the control variables, we found that women who were users of prenatal care services in rural Haiti had an expected number of 3.78 prenatal visits. Many important factors predicted the levels of utilization for the users of prenatal care in rural Haiti. We found that the education of both the mother and the partner was positively and significantly related to the number of prenatal visits. Protestantism was significantly and negatively related to the number of prenatal care visits undertaken by the women users. Other factors that were positively related to the number of visits included the mother's body mass index, the fact that she had

TABLE 3. Incidence rate ratio for prenatal care visits estimated from negative binomial regressions for mothers who reported at least one prenatal visit in urban and rural Haiti, ${ }^{a} 2000$

\begin{tabular}{|c|c|c|c|c|}
\hline \multirow[b]{2}{*}{ Variable } & \multicolumn{2}{|c|}{$\begin{array}{c}\text { Rural } \\
(n=1760)\end{array}$} & \multicolumn{2}{|c|}{$\begin{array}{c}\text { Urban } \\
(n=909)\end{array}$} \\
\hline & $\begin{array}{l}\text { Incidence } \\
\text { rate ratio }\end{array}$ & $\begin{array}{l}\text { Standard } \\
\text { error }\end{array}$ & $\begin{array}{l}\text { Incidence } \\
\text { rate ratio }\end{array}$ & $\begin{array}{c}\text { Standard } \\
\text { errors }\end{array}$ \\
\hline Age $15-24$ & 1.00 & - & 1.00 & - \\
\hline Age 25-34 & 1.0536 & 0.0354 & 1.0459 & 0.0425 \\
\hline Age 35-49 & 1.0168 & 0.0441 & 0.9829 & 0.0557 \\
\hline No education & 1.00 & - & 1.00 & - \\
\hline Primary education & 1.0335 & 0.0315 & $1.1211^{\mathrm{c}}$ & 0.0554 \\
\hline Secondary education & $1.2205^{\mathrm{b}}$ & 0.0625 & $1.2654^{\mathrm{b}}$ & 0.0729 \\
\hline Atheist & 1.00 & - & 1.00 & - \\
\hline Protestant & $0.8952^{c}$ & 0.0456 & 1.0223 & 0.0671 \\
\hline Catholic & 0.9118 & 0.0455 & 0.9865 & 0.0625 \\
\hline Single & 1.00 & - & 1.00 & - \\
\hline Married or cohabiting & 1.0606 & 0.0521 & $1.1202^{c}$ & 0.0054 \\
\hline Number of children under five in household & 0.9887 & 0.0129 & $0.9584^{c}$ & 0.0168 \\
\hline Mother's age at first birth & 1.0046 & 0.0037 & 1.0079 & 0.0042 \\
\hline Ever had an abortion & 0.9737 & 0.0372 & 1.0021 & 0.0476 \\
\hline Ever used contraception & $1.1444^{b}$ & 0.0305 & 1.0598 & 0.0375 \\
\hline Wanted most recent pregnancy & $1.0681^{\mathrm{c}}$ & 0.0290 & $1.1178^{b}$ & 0.0366 \\
\hline Employed sometime in the past 12 months & 0.9752 & 0.0254 & 1.0449 & 0.0333 \\
\hline Body mass index & $1.0001^{\mathrm{b}}$ & 0.0000 & $1.0001^{\mathrm{b}}$ & 0.0000 \\
\hline Smoker & 1.0408 & 0.0705 & 1.1464 & 0.0929 \\
\hline Aware of where to go for pregnancy complications & 1.0691 & 0.0537 & 0.9595 & 0.9595 \\
\hline Partner has no education & 1.00 & - & 1.00 & - \\
\hline Partner has primary education & $1.0683^{\mathrm{c}}$ & 0.0325 & 1.0643 & 0.0554 \\
\hline Partner has at least secondary education & $1.2442^{b}$ & 0.0512 & $1.1742^{b}$ & 0.0621 \\
\hline Received support from relatives and family members & 1.0056 & 0.0256 & 0.9725 & 0.0305 \\
\hline Distance to nearest hospital & 1.0001 & 0.0006 & 0.9985 & 0.0009 \\
\hline Distance to nearest health center & $0.9983^{b}$ & 0.0006 & 0.9996 & 0.0017 \\
\hline Roads represented major difficulties & 0.9978 & 0.0266 & 0.9498 & 0.0387 \\
\hline
\end{tabular}

a Incidence rate ratios (IRRs) were calculated as $\mathrm{e}^{\beta}$, where $\mathrm{e}$ is the exponential and $\beta$ is the coefficient estimated from the negative binomial regression.

b Statistically significant, $P \leq 0.01$.

c Statistically significant, $P \leq 0.05$. 
used a contraceptive method, and that she had wanted the pregnancy. As expected, we found that greater distance to health centers or dispensaries providing medical services in the rural areas significantly reduced the number of prenatal care visits among mothers who decided to seek prenatal care.

Mothers in urban areas. The results for the negative binomial regressions of the levels of prenatal care service utilization among women of childbearing age in urban Haiti who had both given birth and used prenatal care services during the three years preceding the interview date are given in the last two columns of Table 3. Estimated at the mean values of the control variables, the expected number of prenatal visits for urban mothers who used prenatal care services was 5.06 visits. Both primary education and secondary education were important predictors of the number of visits among women who used prenatal care services in urban Haiti. However, only the partner's secondary education was a significant predictor. Being married or cohabiting significantly increased the number of prenatal visits, while having children under 5 years old in the household reduced the number of prenatal visits among the urban mothers who sought prenatal care. Finally, we found that the mother's body mass index and the fact that she had wanted the latest pregnancy were significantly and positively related to the number of prenatal care visits.

\section{DISCUSSION AND CONCLUSIONS}

This study examined the determinants of utilization of prenatal care services in urban and rural Haiti. The main results were that women in rural Haiti who had given birth during the three years preceding the interview date were significantly less likely to use prenatal care, compared to mothers who lived in cities. Estimated at the mean values of the control variables, the expected probability of using prenatal care services in rural Haiti was $77.16 \%$, compared to $85.83 \%$ in urban Haiti, a difference of $8.67 \%$. Our re- sults also indicate that among mothers who used prenatal care services, those in rural Haiti had an expected number of 1.28 fewer prenatal care visits (3.78 expected visits), compared to mothers in cities (5.06 expected visits).

The 1994 Summit of the Americas, which was held in the city of Miami, Florida, United States, concluded that health reforms must comprehensively address the various cultural, geographical, and financial barriers that determine inequity in access to health care among marginalized populations (39). Public health programs have long aimed at improving mothers' health and their awareness of the role of prenatal care in reducing the incidence of low birthweight and of infant mortality. More recently, the potential of the prenatal care period as an entry point for the prevention of HIV transmission from mother to children has led to renewed interest in access to and use of prenatal care (40).

The findings of our study suggest access to prenatal care services in Haiti compared favorably to the average of $68 \%$ for all mothers in developing countries (40). Little rigorous scientific evaluation of prenatal care programs in developing countries has been conducted to determine their effectiveness (40), but World Health Organization guidelines recommend four visits for normal pregnancies. Users of prenatal care in urban Haiti received an average of five prenatal visits, but the mothers in rural areas who decided to seek prenatal care services fell slightly below the recommended four visits.

Overall, the education level of both mothers and their partners was found to be an important predictor of the decision to seek prenatal care services in both urban and rural Haiti. Previous research has also suggested that education may impact health through a number of avenues, including the tendency of educated people to take preventive care measures and to have greater levels of health literacy and control over their lives (41). The importance of basic education in predicting prenatal care utilization was particularly apparent in the rural areas of Haiti. Thus, policies addressing inequalities in access to care in the country should also aim at improv- ing basic education, which is an important factor in mediating the "income effect" on inequalities (41). In both Chile and Japan, for example, investments in universal primary education did improve health care $(42,43)$.

In addition, greater efforts in Haiti should be directed toward providing the necessary training, equipment, and supplies for the auxiliary nurses and midwives in rural areas, while recognizing that for complicated cases more specialized skills, such as those of a doctor or an obstetrician/gynecologist, should be available at a manageable distance. We found that longer travel times and greater distances to dispensaries in rural areas constituted substantial barriers to repeated prenatal visits among the women who sought prenatal care. This is an expression of a larger problem in most developing countries, where most of the public spending on health care is directed toward hospitals and specialist care in urban areas, at the expense of rural primary care facilities. Researchers working in Ghana found that reducing the average distance to the nearest facility resulted in a significant increase in primary care use (44). Programs in rural Haiti should address the issue of travel time to the nearest facility that has the needed services.

Our study presents important findings on access to prenatal care for women in Haiti, with special emphasis on disadvantaged mothers in rural areas. We did not model other key elements of effective prenatal care, such as timing of first visit and use of vitamin supplements. Nevertheless, the policy significance of our findings remains high since evidence-based policy is rare in Haiti, given that little scientific information exists on access to and use of health care services. Such information may be crucial for policymakers and health care providers as they consider and decide on service delivery and management.

Acknowledgments. We thank ORC Macro International and the Institut Haitien de l'Enfance for allowing us to use the data set for this study. We also thank the three anonymous reviewers for their very constructive comments. 


\section{REFERENCES}

1. Pan American Health Organization. Health situation analysis and trends analysis. Country health profile 2002. Haiti [Web page]. Available from: http://www.paho.org/ English/DD/AIS/cp_332.htm. Accessed 31 May 2005.

2. World Bank. Haiti: the challenges of poverty reduction. Washington, D.C.: World Bank; 1998.

3. Cayemittes M, Placide MF, Barrere B, Mariko $S$, Severe B. Enquête Mortalité, Morbidité et Utilisation des Services, Haïti 2000. Calverton: Ministère de la Santé Publique et de la Population, Institut Haïtien de l'Enfance et ORC Macro; 2001.

4. Andersen RM. Revisiting the behavioral model and access to medical care: does it matter? J Health Soc Behav. 1995;36:1-10.

5. Andersen R, Newman JF. Societal and individual determinants of medical care utilization in the United States. Milbank Mem Fund Q Health Soc. 1973;51:95-124.

6. Grossman M. The demand for health: a theoretical and empirical investigation. New York: Columbia University Press, for the National Bureau of Economic Research; 1972.

7. Grossman M. On the concept of health capital and the demand for health. J Polit Econ. 1972; 80:223-5.

8. Rosenzweig MR, Schultz TP. Estimating a household production function: heterogeneity, the demand for health inputs and their effects on birth weight. J Polit Econ. 1983;91: 723-46.

9. Phelps CE. Health economics. New York: Harper Collins; 1997.

10. Folland S, Goodman AG, Stano M. The economics of health care. Englewood Cliffs: Prentice Hall; 2001.

11. Duan N, Manning WG Jr, Morris CN, Newhouse JP. A comparison of alternative models for the demand for medical care. J Bus Econ Stat. 1983;1:115-26.

12. Cameron AC, Trivedi PK. Regression analysis of count data. Cambridge: Cambridge University Press; 1998.

13. Deb P, Trivedi PK. Demand for medical care by the elderly: a finite mixture approach. J Appl Econom. 1997;12:313-36.

14. Gurmu S. Semi-parametric estimation of hurdle regression models with an application to Medicaid utilization. J Appl Econom. 1997;12: $225-42$.

15. Mullahy J. Instrumental variables estimation of Poisson regression models: applications to models of cigarette smoking behavior. Rev Econ Stat. 1997;79:586-93.

16. Deb P, Holmes AM. Estimates of use and costs of behavioural health care: a comparison of standard and finite mixture models. Health Econ. 2000;9:475-89.

17. Watts CA, Scheffler RM, Jewell NP. Demand for outpatient mental health services in a heavily insured population: the case of the Blue Cross and Blue Shield Association's Federal Employees Health Benefits Program. Health Serv Res. 1986;21:267-89.

18. Horgan CM. The demand for ambulatory mental health services from specialty providers. Health Serv Res. 1986;21:291-319.

19. Scheffler RM, Miller AB. Demand analysis of mental health service use among ethnic subpopulations. Inquiry. 1989;26:202-15.

20. Haas-Wilson D, Cheadle A, Scheffler R. The demand for mental health services: an episode of treatment approach. Southern Econ J. 1989;56:219-32.

21. Zweifel P. Supplier-induced demand in a model of physician behavior. In: van der Gaag J, Perlman M, eds. Health, economics, and health economics. New York: North-Holland Pub. Co.; 1981. Pp. 245-67.

22. Mullahy J. Much ado about two: reconsidering the two-part model in health econometrics. J Health Econ. 1998;17:247-81.

23. Holmes AM, Deb P. Provider choice and use of mental health care: implications for gatekeeper models. Health Serv Res. 1998;33: 1263-84.

24. Duan N, Manning WG Jr, Morris CN, Newhouse JP. Choosing between the sampleselection model and the multi-part model. J Bus Econ Stat. 1984;2(3):283-9.

25. Manning WG. The logged dependent variable, heteroscedasticity, and the retransformation problem. J Health Econ. 1998;17(3): 283-95.

26. Greene WH. Econometric analysis. 5th ed. Upper Saddle River: Prentice Hall; 2003.

27. Obermeyer CM, Potter JE. Maternal health care utilization in Jordan: a study of patterns and determinants. Stud Fam Plann. 1991;22: $177-87$.

28. Magadi MA, Madise NJ, Rodrigues RN. Frequency and timing of antenatal care in Kenya: explaining the variations between women of different communities. Soc Sci Med. 2000;51: $551-61$.

29. McCaw-Binns A, Grenade JL, Ashley D. Under-users of antenatal care: a comparison of non-attenders and late attenders for antenatal care, with early attenders. Soc Sci Med. 1995;40:1003-12.

30. Bhatia JC, Cleland J. Self-reported symptoms of gynecological morbidity and their treatment in south India. Stud Fam Plann. 1995; 26:203-16.

31. Misra US, Roy TK, Rajan Irudaya S. Antenatal care and contraceptive behaviour in India: some evidence from the National Family Health Survey. J Fam Welf. 1998;44:1-14.

32. Pallikadavath S, Foss M, Stones WR. Antenatal care: provision and inequality in rural north India. Soc Sci Med. 2004;59(6):1147-58.

33. Taguchi N, Kawabata M, Maekawa M, Maruo $\mathrm{T}$, Aditiawarman, Dewata L. Influence of socio-economic background and maternal care programmes on maternal mortality in Surabaya, Indonesia. Trop Med Int Health. 2003;8:847-52.

34. Finerman R. The forgotten healers: women as family healers in an Andean Indian community. In: McClain CS, ed. Women as healers: cross-cultural perspectives. New Brunswick: Rutgers University Press; 1989. Pp. 122-34.

35. McKee L. Ethnomedical treatment of children's diarrheal illnesses in the Highlands of Ecuador. Soc Sci Med. 1987;25:1147-55.

36. Wiley AS. Increasing use of prenatal care in Ladakh (India): the roles of ecological and cultural factors. Soc Sci Med. 2002;55:1089-1102.

37. Kitzinger A. Becoming a grandmother: a life transition. New York: Scribner; 1996.

38. Acharya LB, Cleland J. Maternal and child health services in rural Nepal: does access or quality matter more? Health Policy Plan. 2000;15:223-9.

39. Summit of the Americas Information Network. First Summit of the Americas. Miami, Florida December 9-11,1994. Declaration of Principles [Web page]. Available from: http:// www.summit-americas.org/miamidec.htm. Accessed 31 May 2005.

40. Carroli G, Villar J, Piaggio G, Khan-Neelofur D, Gulmezoglu M, Mugford M, et al. WHO systematic review of randomised controlled trials of routine antenatal care. Lancet. 2001; 357:1565-70.

41. Wagstaff A. Socioeconomic inequalities in child mortality: comparisons across nine developing countries. Bull World Health Organ. 2000;78(1):19-29.

42. Vega J. Chile: socioeconomic differentials and mortality in a middle-income nation. In Evans T, Whitehead M, Diderichsen F, Bhuiya A, Wirth M, eds. Challenging inequities in health: from ethics to action. New York: Oxford University Press; 2001. Pp. 123-36.

43. Hasegawa T. Japan: historical and current dimensions of health and health policy. In: Evans T, Whitehead M, Diderichsen F, Bhuiya A, Wirth $\mathrm{M}$, eds. Challenging inequities in health: from ethics to action. New York: Oxford University Press; 2001. Pp. 91-103.

44. World Bank. The effect of quality and cost in health care choice in developing countries. Washington, D.C.: World Bank; 1993.

Manuscript received 10 June 2004. Revised manuscript accepted for publication 9 March 2005. 
RESUMEN Objetivos. El presente estudio se basa en la Encuesta de Demografía y Salud del año 2000 en Haití. Los objetivos del estudio, que se basó en información sobre las mujeres de 15 a 49 años de edad que habían dado a luz en los tres años anteriores a la entre-

El uso de servicios de atención prenatal en áreas rurales y urbanas de Haití

Palabras clave vista, fueron: 1) examinar los factores que determinan la probabilidad de que las mujeres acudan a atención prenatal en las zonas rurales y urbanas del país y 2) dentro del grupo de mujeres con una o más consultas prenatales, examinar los factores que determinan el número de dichas consultas en las zonas rurales y urbanas.

Métodos. En el análisis multifactorial se emplearon modelos logísticos para determinar qué factores explicaban la decisión de acudir a control prenatal, y se usaron modelos binomiales negativos para determinar el número de consultas prenatales dentro del subgrupo de mujeres que consultaron por lo menos una vez.

Resultados. La probabilidad esperada de acudir a control prenatal, determinada según el valor medio de las variables de control, fue de $77,16 \%$ en las zonas rurales, en comparación con $85,83 \%$ en las zonas urbanas de Haití. Dentro del grupo de mujeres que acudieron a servicios de control prenatal, las madres en zonas rurales tuvieron un número esperado de consultas prenatales de 3,78, en comparación con 5,06 en las zonas urbanas.

Conclusiones. Un buen porcentaje de mujeres embarazadas tiene acceso a servicios de atención prenatal en Haití, pero las madres en zonas rurales que eligieron acudir a dichos servicios tuvieron un poco menos del mínimo de cuatro consultas recomendado por la Organización Mundial de la Salud. El nivel educativo de las madres y de sus parejas es un factor pronóstico muy importante en relación con el uso de servicios de atención prenatal. Las consultas repetidas se vieron obstaculizadas en las zonas rurales por el mayor tiempo de desplazamiento y la mayor distancia hasta el centro de salud. Los formuladores de políticas y los proveedores de atención sanitaria deben tener en cuenta estos resultados a la hora de tomar decisiones sobre la prestación y administración de los servicios de salud en Haití.

Atención prenatal, servicios rurales de salud, servicios urbanos de salud, Haití.

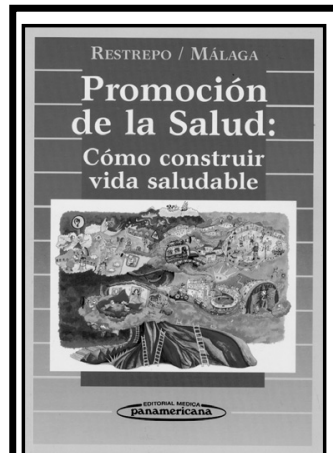

Promoción de la salud: cómo construir vida saludable

Con el noble empeño de despertar conciencia sobre la importancia de "construir salud" mediante la promoción de la salud, los autores de este libro hacen un aporte inestimable a las instituciones y personas que tienen la responsabilidad de fomentar el bienestar de las poblaciones. En América Latina se hace imprescindible el trabajo dirigido hacia la promoción de la salud, como única opción para reducir las brechas existentes en la salud y el bienestar de las personas.

Este libro profundiza los conceptos teóricos y prácticos de la promoción de la salud como meta para avanzar en la búsqueda de la equidad en los niveles locales, con la aplicación de diversas estrategias adaptadas a los entornos en que las personas viven y trabajan.

2001 • 298 pp. • ISBN 9589181554 • Código: OT 129 • Precio: US\$ 25.00/US\$ 20 en América Latina y el Caribe http://publications.paho.org • Fax: (301) 206-9789 • Correo electrónico:paho@pmds.com 